Review

\title{
Khat chewing, cardiovascular diseases and other internal medical problems: The current situation and directions for future research
}

\author{
A. Al-Motarreb ${ }^{\mathrm{a}}$, M. Al-Habori ${ }^{\mathrm{b}}$, K.J. Broadley ${ }^{\mathrm{c}, *}$ \\ a Cardiac Centre, Internal Medicine Department, Sana'a University, Sana'a, Yemen \\ b Biochemical Department, Faculty of Medicine, Sana'a University, Sana'a, Yemen \\ ' Division of Pharmacology, Welsh School of Pharmacy, Cardiff University, King Edward VII Avenue, Cardiff CF10 3NB, UK
}

\section{A R T I C L E I N F O}

\section{Article history:}

Received 9 October 2009

Received in revised form 4 June 2010

Accepted 1 July 2010

Available online 17 July 2010

\section{Keywords:}

Khat

Myocardial infarction

Hypertension

Vasoconstriction

Cathinone

\begin{abstract}
A B S T R A C T
The leaves of khat (Catha edulis Forsk.) are chewed as a social habit for the central stimulant action of their cathinone content. This review summarizes the prevalence of the habit worldwide, the actions, uses, constituents and adverse health effects of khat chewing. There is growing concern about the health hazards of chronic khat chewing and this review concentrates on the adverse effects on health in the peripheral systems of the body, including the cardiovascular system and gastrointestinal tract. Comparisons are made with amphetamine and ecstasy in particular on the detrimental effects on the cardiovascular system. The underlying mechanisms of action of khat and its main constituent, cathinone, on the cardiovascular system are discussed. Links have been proposed between khat chewing and the incidence of myocardial infarction, dilated cardiomyopathy, vascular disease such as hypertension, cerebrovascular ischaemia and thromboembolism, diabetes, sexual dysfunction, duodenal ulcer and hepatitis. The evidence, however, is often based on limited numbers of case reports and only few prospective controlled studies have been undertaken. There is therefore an urgent need for more thorough case-control studies to be performed. This review outlines the current knowledge on the adverse health effects of khat chewing on the cardiovascular system and other internal medical problems, it assesses the evidence and the limitations of the studies and identifies the questions that future studies should address.
\end{abstract}

(C) 2010 Elsevier Ireland Ltd. All rights reserved.

\section{Contents}

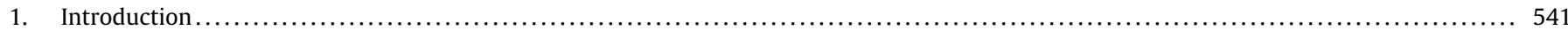

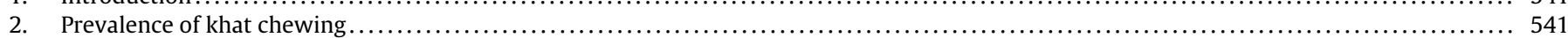

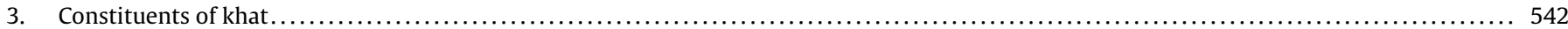

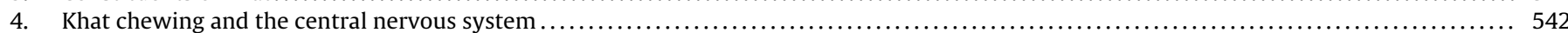

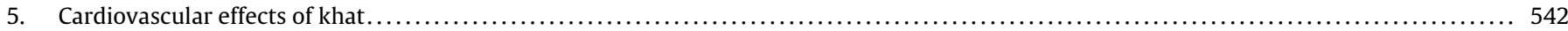

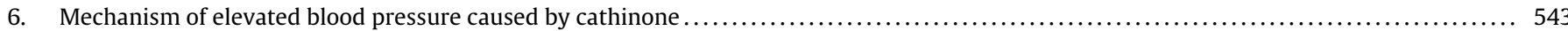

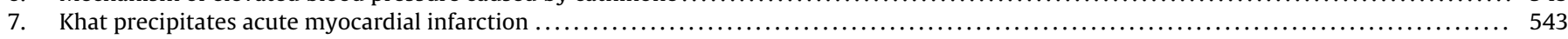

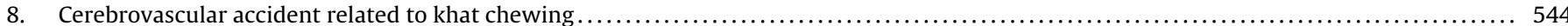

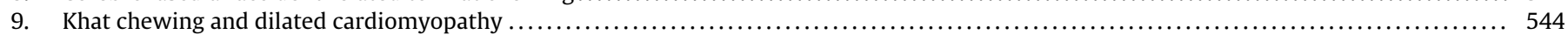

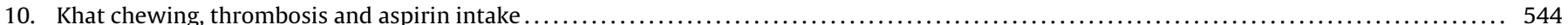

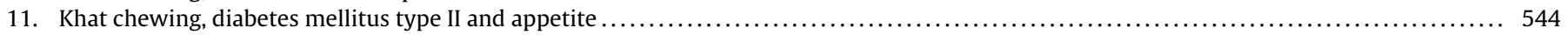

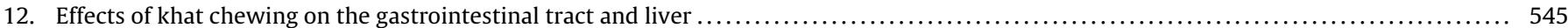

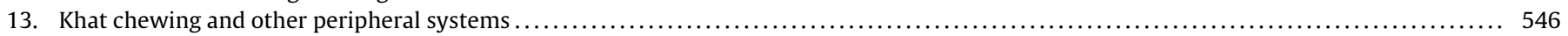

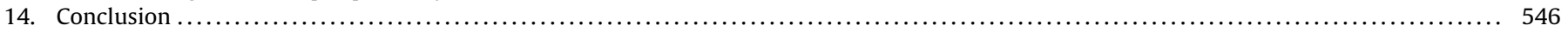

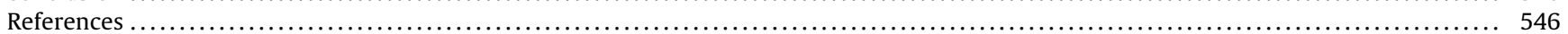

\footnotetext{
* Corresponding author. Tel.: +44 029 20875832; fax: +44 02920874149.

E-mail address: BroadleyKJ@Cardiff.ac.uk (K.J. Broadley).
} 


\section{Introduction}

Chewing the leaves of khat or qat (Catha edulis Forsk.) is a social habit in Yemen and East African countries. People chew fresh khat leaves (Fig. 1) daily on a regular basis mainly in the afternoon, although some people start to chew khat in the morning. Social gatherings like wedding parties, funerals and at election time have made khat chewing more popular. At the present time, easy transportation of khat and easing of importation restrictions has helped this habit spread to countries such as the USA and Western Europe where Yemeni, Somali and other East African communities are living (Griffiths, 1998; Manghi et al., 2009). Euphoria, alertness and central nervous system stimulation induced by cathinone, the main active constituent derived from khat chewing, makes this habit popular among large numbers of society. Khat chewing was linked to the body's physical health many centuries ago and was mentioned as a medicine by an Arabic physician, Abu Al-Rihan Bin Ahmed Al-Baironi (973-1051 AD), in his book Pharmacy and Therapeutic Art (El-Tahir, 1990). It had been used for the management of

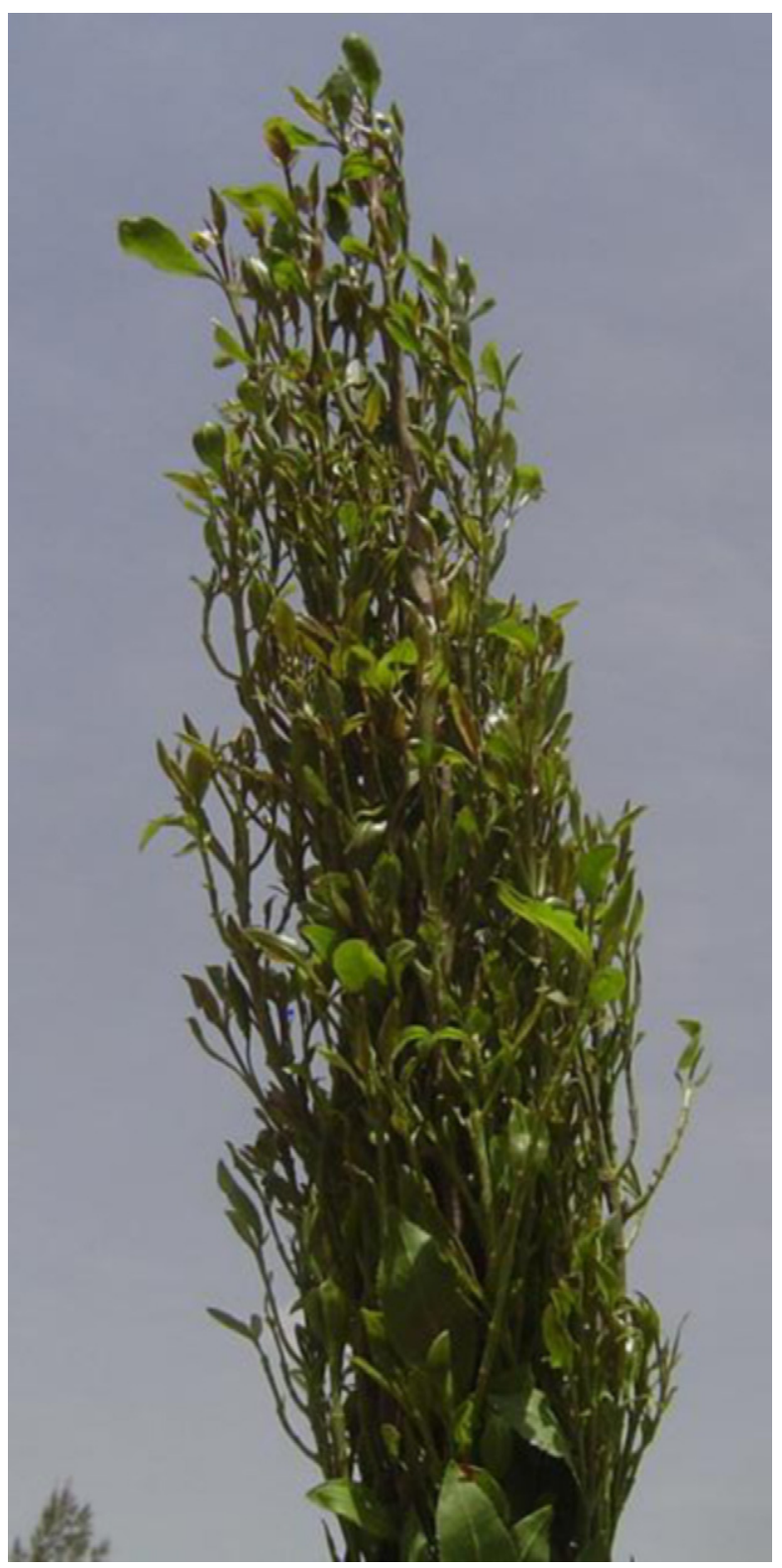

Fig. 1. A bundle of khat (Catha edulis Forsk). obesity and depression due to its central stimulant effects (Al-Attas, 1981). Religious scholars used to chew khat to be alert during the night time to study religious science. Many factors played a role in the extension to its social use in society; easy transportation from village to city khat market, the availability of cheap khat making it affordable for all and afternoon free time because work officially finishes at 2:00 pm in the Yemen. People also believe that khat helps them to work more effectively, particularly with manual work, due to increased energy and alertness. Khat chewing, however, has been reported to have adverse effects on various human body systems. Recently, khat chewing has become a real national problem in the Yemen and many people, in particular physicians, believe that khat chewing can damage health and have grave social, financial and medical consequences (Khalil, 1997; Manghi et al., 2009). There is now growing concern of its health effects worldwide (Manghi et al., 2009). There have been a number of reviews of the effects of khat chewing (Halbach, 1972; Al-Meshal et al., 1985; Pantelis et al., 1989; Al-Motarreb et al., 2002a; Cox and Rampes, 2003; Al-Habori, 2005; Hassan et al., 2007) and this article supplements those earlier reviews to concentrate on the adverse health effects in a number of peripheral systems, with a focus on the cardiovascular side effects of khat use. This review does not deal with the psychological and neuropharmacological properties of khat chewing which can be found in recent reviews (Feyissa and Kelly, 2008). Other adverse health effects such as the incidence of oral diseases, including periodontitis, oral leukoplakia and oral cancer, associated with khat chewing are also reviewed elsewhere (El-Wajeh and Thornhill, 2009).

\section{Prevalence of khat chewing}

Khat use is highly prevalent in East African and Middle Eastern countries, in particular the Yemen (Manghi et al., 2009). Figures for the numbers of individuals who chew khat in the general populations of individual countries is mainly anecdotal, however, surveys have been performed to determine the exact incidence of khat chewing among specific cohorts. 15 years ago, Kalix mentioned 6 million daily khat users (Kalix, 1996). Khat chewing among male Aden University medical students increased from $35 \%$ to $90 \%$ over the 5 years of training (Laswar and Darwish, 2009). In college and high school students of Jazan region of Saudi Arabia aged between 15 and 25 years, $37.7 \%$ of males and only $3.8 \%$ of females chewed khat (Ageely, 2009). 15.9\% of a sample of 4001 men in Addis Ababa, Ethiopia regularly chewed khat (Tesfaye et al., 2008). There is evidence that khat use in Ethiopia is more prevalent in ethnic communities with a tradition of khat use but it is now becoming an every-day drug for the general population (Alem et al., 1999; Belew et al., 2000). The prevalence of khat chewing in Western countries appears to be restricted to the immigrant communities from these countries where there is still a high prevalence among the immigrant groups (Manghi et al., 2009). In the UK, 75 male Yemeni adults reported chewing up to 3 bundles of khat per week of which $39 \%$ were assessed as dependent (Kassim and Croucher, 2006). In Somali communities of the UK, approximately 1 third chew khat on a regular basis (Patel et al., 2005). Khat chewing is also an emerging problem in Australia (Stefan and Mathew, 2005) and among Somali immigrants in Norway (Al-Samarraie et al., 2007). The Dutch Minister of Health requested a risk evaluation for khat in order to decide upon its legal status in the Netherlands (Pennings et al., 2008). The report concluded that chronic toxicity of khat was modest when used in low amounts but high use was associated with hypertension, heart rhythm disorders, loss of appetite and a high incidence of cancers in the digestive tract. In the population at large of the Netherlands and other countries, khat chewing does not represent a high health risk as its use is restricted to East African immigrants. 
<smiles>CC(N)Cc1ccccc1</smiles>
$S-(+)-A m p h e t a m i n e$

$1 R, 2 S-(-)-$ Norephedrine<smiles>C[C@@H](N)[C@H](O)c1ccccc1</smiles><smiles>C[C@H](N)C(=O)c1ccccc1</smiles>

\section{S-(-)-Cathinone}

$1 S, 2 S-(+)-C$ athine (Norpseudoephedrine)<smiles>C[C@@H](N)[C@H](O)c1ccccc1</smiles><smiles>CCCCNC(C)Cc1ccc2c(c1)OCO2</smiles>

Fig. 2. Chemical structures of the primary alkaloid constituents of khat, cathinone, cathine (norpseudoephedrine) and norephedrine, compared with amphetamine and 3,4-methylenedioxymethamphetamine (MDMA, 'ecstasy').

There is some evidence that khat use has spread to the host population. For example, a pill containing extract of khat leaves known as "Hagigat" has been sold to Israeli drug users (Bentur et al., 2008). It is also spreading to non-ethinic users in the UK (Holligan, 2009). Khat is illegal in the USA, Canada and many European Countries including Denmark, Finland, Ireland, France, Germany, Switzerland, Norway and Sweden.

\section{Constituents of khat}

There are three main alkaloids present in khat leaves (Kalix, 1988, 1992): S-(-)-cathinone (s- $\alpha$-aminopropriophenone), norepseudoephedrine (cathine) and norephedrine.

There are also small amounts of ethereal oil, sterols and triterpenes, together with $5 \%$ protein which has insignificant nutritional value. Ascorbic acid is also present in the leaves (Raman, 1983). Khat leaves also contains tannin (7-14\% by weight in dried leaves) and minute amount of thiamin, niacin, riboflavin, iron and amino acids (Lugman and Danowski, 1976). Apart from tannin, these substances are unlikely to contribute to the biological effect of khat (Kalix, 1984, 1992). S-(-)-cathinone is relatively unstable and decomposes within a few days of picking or if the leaf is dried into (+)-norpseudoephedrine and norephedrine. Thus, only freshly picked leaves have the full efficacy. Norpseudoephedrine and norephedrine are slowly absorbed and then excreted mainly unchanged within about $24 \mathrm{~h}$ (Brenneisen et al., 1986). The major metabolites of S-(-)-cathinone after ingestion are R,S-(-)norephedrine and R,R-(-)-norpseudoephedrine (Brenneisen et al., 1986), which have weaker sympathomimetic activities and central stimulant properties.

\section{Khat chewing and the central nervous system}

Khat leaves contain the psychoactive alkaloid cathinone, which is structurally similar to D-amphetamine (Fig. 2). Cathinone, like 3,4-methylenedioxymethamphetamine (MDMA, 'ecstasy') and amphetamine, exerts pronounced behavioural effects including euphoria, excitability, anxiety, irritability, hyperactivity, restlessness and insomnia (Cox and Rampes, 2003). The central nervous activity of cathinone is qualitatively and quantitatively similar to that of amphetamine (Kalix, 1984). This is followed by lethargy and sleepiness the next morning. Depression and psychosis occur mainly among heavy khat chewers (Odenwald et al., 2005). There is also hyperthermia (Kalix, 1984; Kalix and Braenden, 1985). Khat usage is associated with memory impairment, depression and psychoses (Houghton, 2004) and the World Health Organisation classifies khat as causing psychological but not physical dependence, with daily consumption causing negative effects on the social and economic life of the user (WHO, 2006). The adverse effects of khat in the central nervous system, as in other systems, are dose-related (Alem and Shibre, 1997; Cox and Rampes, 2003). As with other recreational drugs, heavy khat chewing precipitates psychosis in those who are already predisposed (Cox and Rampes, 2003; Odenwald et al., 2005) and might exacerbate symptoms in patients with pre-existing psychiatric disorders (Hassan et al., 2002). Khat withdrawal is an effective treatment of khat psychosis (Degraeve, 2007) and antipsychotic medications have been used to alleviate symptoms (Jager and Sireling, 1994). Cathinone has a similar mechanism of action to that of amphetamine, acting by releasing catecholamines from presynaptic storage sites (Kalix 1992). Cathinone and amphetamine induce dopamine release from central dopaminergic nerve terminals thus increasing the activity of dopaminergic pathways.

\section{Cardiovascular effects of khat}

Regular khat chewing is associated with elevated mean diastolic blood pressure (Tesfaye et al., 2008). Khat chewing by human volunteers increases blood pressure which coincides with elevated plasma levels of cathinone (Brenneisen et al., 1990; Widler et al., 1994), the peak occurring at 1.5-3.5 h (Halket et al., 1995). Cathinone increases blood pressure, has positive inotropic and chronotropic actions in isolated atria (Gugelmann et al., 1985) and increases heart rate in anaesthetized rats (Kalix and Braenden, 1985) and dogs (Kohli and Goldberg, 1982). Vasoconstriction from electrical field stimulation is potentiated and claimed to arise from enhanced noradrenaline release (Kalix, 1992). At the peripheral noradrenaline storage site, where $\mathrm{S}-(-)$-cathinone acts like amphetamine, the noradrenaline releasing effect of S-(-)cathinone was abolished by the noradrenaline reuptake inhibitors, cocaine or desipramine (Kalix, 1983). These observations suggested that cathinone was acting as an indirectly acting sympathomimetic amine (Fig. 3).

In guinea-pig isolated perfused hearts, cathinone causes a marked constriction of the coronary vasculature, the maximum being equivalent to that achieved with noradrenaline or the cathinone metabolite, norpseudoephedrine. There was also a pronounced negative inotropy, possibly due to the impared coronary perfusion (Al-Motarreb and Broadley, 2003). The vasoconstriction was not inhibited by cocaine $(10 \mu \mathrm{M})$ suggesting that the response was not an indirect sympathomimetic action. Cathinone (Fig. 4) and MDMA both produced coronary vasoconstriction in pig isolated left anterior descending coronary artery rings. The vasoconstrictor response to cathinone was also not inhibited by cocaine or the $\alpha_{1}$-adrenoceptor antagonist, prazosin (Fig. 4) (Baker et al., 2007). This result suggests that the vasoconstriction in this vessel was not mediated via either a direct or indirect sympathomimetic mechanism. This finding contrasts with the pharmacology of cathinone at other sites where it is reported to have indirect actions by releasing noradrenaline (Kalix, 1983). 


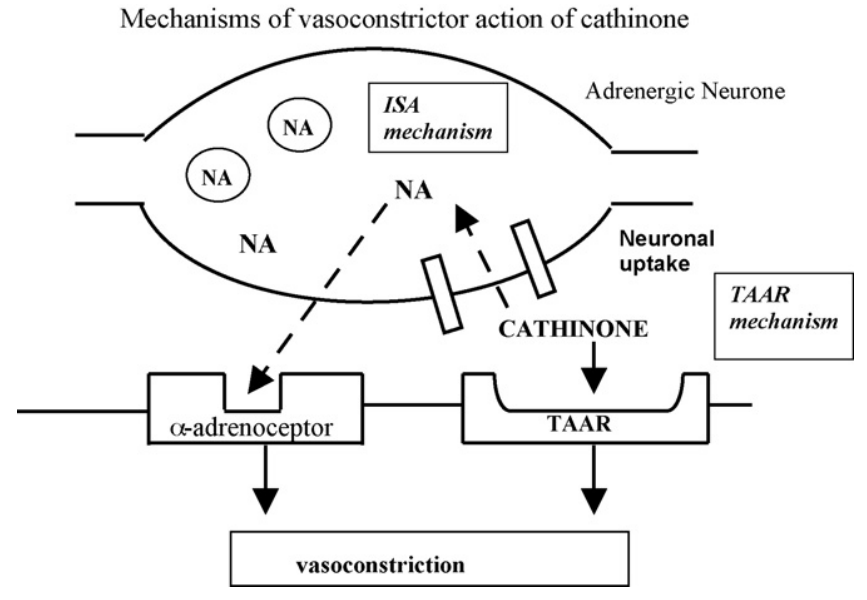

Fig. 3. Mechanisms of the vasoconstrictor actions of cathinone. Cathinone can act as an indirectly acting sympathomimetic amine (ISA mechanism) through uptake into sympathetic neurones and release of noradrenaline (NA) onto $\alpha$-adrenoceptors. It can also act via a sympathomimetic-independent mechanism probably directly on trace amine-associated receptors (TAAR mechanism).

Another vascular complication of chronic khat chewing is a significantly much higher incident of haemorrhoids (Al-Hadrani, 2000). This study showed clear evidence that $62 \%$ of khat chewers had haemorrhoids, of which $45.4 \%$ of the group underwent haemorrhoidectomy, compared with only $4 \%$ of non-chewers displaying haemorrhoids. However, the study did not attempt to examine the roles of confounding influences, such as smoking, diet, age and other disorders of the lower gut such as chronic constipation. It also did not address the question of whether the haemorrhoids were caused by the cathinone in the khat or by other constituents such as the tannins. Thus, further prospective studies are warranted that control for these factors.

\section{Mechanism of elevated blood pressure caused by cathinone}

Khat chewers experience an increase in heart rate, body temperature and sweating. This is associated with cold extremities,

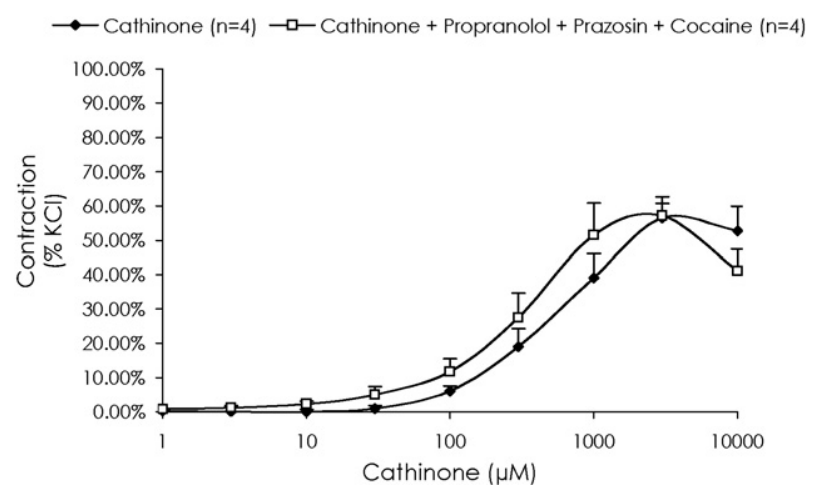

Fig. 4. Mean cumulative concentration-response curves for the contractile effects of cathinone on pig left anterior descending coronary artery. Responses were obtained in the absence $(\downarrow)$ and presence $(\square)$ of prazosin $\left(\alpha_{1}\right.$-adrenoceptor antagonist, $1 \mu \mathrm{M}$ ), propranolol ( $\beta$-adrenoceptor antagonist, $1 \mu \mathrm{M}$ ) and cocaine (neuronal uptake inhibitor, $10 \mu \mathrm{M})$ Responses are the mean $( \pm$ S.E.M. $)(n=4)$ increases in tension at each concentration expressed as a percentage of the contraction to $\mathrm{KCl}$ $(60 \mathrm{mM})$ added at the end of each experiment. Coronary artery rings ( $5 \mathrm{~mm}$ long) were set up in Krebs-bicarbonate solution gassed with $5 \% \mathrm{CO}_{2}$ in oxygen at $37^{\circ} \mathrm{C}$ and attached to isometric tension transducers (Dynamometer, Type UF1, $57 \mathrm{~g}$ sensitivity range) (Ormed, Welwyn Garden City, Hertfordshire). Isometric tension was recorded on a PowerLab/4SP computer system (ADInstruments. Software: Chart v.4.1.1 sampling frequency $4 \mathrm{~Hz}$ ) (Chalgrove, Oxfordshire, UK). a clinical manifestation of the peripheral vasoconstriction caused by khat chewing. Since guinea-pig aortic ring preparations (AlMotarreb and Broadley, 2003) and pig coronary artery rings (Baker et al., 2007) constrict in response to cathinone, vasoconstriction would explain the increase in blood pressure caused by cathinone in anaesthetized animals (Kohli and Goldberg, 1982) and human volunteers (Brenneisen et al., 1990; Hassan et al., 2000). This would also explain a rise in blood pressure of about $15 \mathrm{~mm} \mathrm{Hg}$ after chewing khat (Widler et al., 1994). Whether this is entirely due to the release of noradrenaline from peripheral sympathetic neurons cannot be established at present, since the vasoconstrictor effects of cathinone in isolated blood vessels are independent of either a direct or indirect noradrenergic mechanism. The vasoconstriction of porcine coronary arteries was not blocked by an $\alpha_{1}$-adrenoceptor antagonist, prazosin, or by the neuronal uptake inhibitor, cocaine (Baker et al., 2007). It is possible that the vasoconstriction by cathinone is via the recently identified trace amine-associated receptors for which ecstasy at least has been shown to have affinity (Bunzow et al., 2001) (Fig. 3). The increase in blood pressure after chewing khat was also not blocked by the $\alpha_{1}$-adrenoceptor antagonist, indoramine, confirming a lack of involvement of vascular $\alpha_{1}$-adrenoceptors in the pressor response (Hassan et al., 2005). There is probably a significant cardiac component to the increase in blood pressure after chewing khat through tachycardia, since the increases in blood pressure and heart rate were reduced by the $\beta_{1}$ adrenoceptor antagonist, atenolol (Hassan et al., 2005). It is likely therefore that the residual pressor response is due to stimulation of trace amine-associated receptors by cathinone, further studies are required to confirm this when antagonists of these receptors become available.

\section{Khat precipitates acute myocardial infarction}

Abuse of amphetamines has been shown to be significantly associated with acute myocardial infarction (AMI) with $0.2 \%$ of AMIs in the state of Texas being attributable to amphetamine abuse (Westover et al., 2008). Recently, the khat chewing habit has changed and many chewers extend their chewing time into the evening, sometimes until midnight. This has been associated with a change in the circadian rhythm of presentation with AMI. The most common time for presentation with major cardiovascular events, such as acute myocardial infarction and sudden death, is in the early morning after waking and rising (Selwyn et al., 1991; Detry and Vincent, 1992). This diurnal rhythm is associated with increased sympathetic outflow and circulating catecholamines producing increases in heart rate, blood pressure, myocardial contractility and oxygen demand soon after rising. However, there is a shift in this diurnal rhythm of AMI amongst khat chewers, where a greater proportion presented in the evening compared with non-khat chewers (Al-Motarreb et al., 2002b). In a follow-up case-control study, khat chewing was found to be an independent risk factor for AMI (AlMotarreb et al., 2005). Moderate khat chewers were shown to be at high risk (Odds Ratio, OR $=7.62$ ) and heavy khat chewers were at even higher risk $(\mathrm{OR}=22.28)$. There was a direct relationship between the duration of khat chewing sessions and the risk of AMI; subjects chewing for more than $6 \mathrm{~h}$ were at high risk $(\mathrm{OR}=39$ ). In this study, smoking was considered as a possible confounding issue since many khat chewers are also tobacco smokers and khat chewing increases the desire to smoke. The study showed an independent dose-related risk of MI from both smoking 20 cigarettes a day $(O R=32.98)$ and khat chewing for $6 \mathrm{~h}$ per day ( $O R=39.33)$. The A further study showed that of 120 patients admitted with AMI, a much higher proportion (79\%) were khat chewers than nonchewers (Alkadi et al., 2002). In the same paper, these authors also showed that administration of khat ( $1 \mathrm{~g} / \mathrm{kg}$ three times a day) 
to rabbits over 2 months significantly increased serum levels of the cardiac enzymes, lactate dehydrogenase (LDH) and creatine kinase-iso enzyme (CK-MB), and caused histological changes in the heart consistent with myocardial infarction. The above clinical observations have been supported by laboratory studies on the effects of cathinone on isolated hearts and coronary arteries. Cathinone caused coronary vasoconstriction in guinea-pig isolated hearts (Al-Motarreb and Broadley, 2003) and in pig isolated left anterior descending coronary arteries (Baker et al., 2007), which is not due to indirect or direct sympathomimetic activities. This coronary vasoconstriction by cathinone would explain the increase of acute myocardial infarction among khat chewers due to coronary vasospasm in susceptible individuals. The increase in blood pressure in khat chewers will also raise the risk of AMI. Doctors usually recommend stopping khat chewing as part of changing lifestyle and for better control of patients with high blood pressure. Future studies on the role of khat chewing in risk of MI must separate out other confounding issues, most particularly smoking. Both MI patients and non-MI controls must include equivalent numbers of recruits in the following groups: Khat chewers/non-smokers, khat chewers/smokers, non-chewers/non-smokers, non-chewers/smokers. This will make recruitment of sufficient numbers in each group difficult, but the rewards in the validity and power of the study will be worthwhile.

\section{Cerebrovascular accident related to khat chewing}

The vasoconstrictor effects of cathinone and arterial hypertension produced by khat chewing and the links with myocardial infarction reported above suggest that the same mechanism might occur in the cerebral vasculature. Stroke-like cerebral complications in patient abusing sympathomimetic drugs like cocaine and amphetamine have been observed (Bruno, 2003). Ischaemic stroke after khat chewing has been reported in a 41 years old male patient khat chewer (Vanwalleghem et al., 2006). In another case report, a 28 years old male khat chewer patient developed AMI and cerebrovascular accident after chewing khat, with the suggestion of an increased thrombogenecity as a key factor (de Ridder et al., 2007a,b). Khat chewing has also been reported to increase the incidence of acute cerebral infarction. This is probably due to the significantly higher blood pressure among the acute cerebral infarction khat-chewer patients compared with the control group (Mujalli et al., 2005). However, more definitive studies showing a causal relationship between khat chewing and cerebrovascular accidents are still lacking.

\section{Khat chewing and dilated cardiomyopathy}

Cardiomyopathy has been linked to sympathomimetic agents, in particular amphetamine. Smith et al. (1976) reported a relationship between dilated cardiomyopathy and amphetamine ingestion and Call et al. (1982) described a case of acute heart failure with pulmonary oedema and evidence of myocardial necrosis immediately after intravenous injection of amphetamine. Crean and Pohl (2004) reported a 30 years old woman with dilated cardiomyopathy after long-term amphetamine intake. Cathinone, having identical properties to amphetamine, may have the same effects on the heart muscle and may also produce dilated cardiomyopathy. Indeed, a case report describes an East African man who had chewed khat constantly for 2-3 days presenting with myocardial infarction and 27 months later echocardiography revealed severely impaired biventricular function consistent with ischaemic myopathy (Saha and Dollery, 2006). This article prompted a report by the $\mathrm{BBC}$ warning of the dangers of severe heart problems from khat chewing (BBC, 2006). Al-Saadi and Grigorov (2004) studied
50 Yemeni patients with dilated cardiomyopathy who were regular khat chewers. They investigated the role of different risk factors like khat chewing, alcohol consumption, family history, hypertension, ischaemic heart disease and diabetes, and concluded that khat chewing contributes to the occurrence of dilated cardiomyopathy in young patients with an inherited predisposition. Khat-related dilated cardiomyopathy needs further studies, with myocardial biopsy performed in post-infarct patients to confirm the extent of myopathy.

\section{Khat chewing, thrombosis and aspirin intake}

Aspirin as a preventive therapy against cardiovascular events is widely recommended for healthy people as well as patients with ischaemic heart diseases. A low daily dose of aspirin $(75 \mathrm{mg})$ is used for the long-term prevention of heart attack and stroke. The bleeding time in myocardial infarction patients taking long-term aspirin (100 mg daily) was significantly reduced in khat chewers to 2.3 min compared with $8 \mathrm{~min}$ in non-khat chewers taking the same dose of aspirin (Alkadi et al., 2008). This finding suggested that a constituent of khat attenuates the antiplatelet aggregating properties of aspirin, thereby neutralizing the beneficial actions of aspirin. Adrenaline induces aggregation of human platelets which is mediated via $\alpha_{2}$-adrenoceptors (Broadley, 1996). Thus, it is possible that cathinone by releasing catecholamines can have a pro-aggregatory action. This hypothesis needs testing both experimentally in in vitro aggregation tests and in the clinic. Does cathinone promote platelet aggregation in vitro via $\alpha_{2}$-adrenoceptor stimulation or via trace amine-associated receptors? Do cathinone or khat chewing elevate the levels of adrenaline to the circulation and does the blood show increased platelet aggregation and clotting properties?

A 28-year-old male khat chewer admitted with both AMI and cerebral infarction revealed thrombus occlusions of cerebral artery and proximal right coronary artery. It was concluded that increased thrombogenecity among khat chewers is as key factor for cardiovascular complication (de Ridder et al., 2007a,b). Another male khat chewer admitted with MI showed stenosis in the left anterior descending coronary artery and filling defects consistent with thrombus formation (Saha and Dollery, 2006). Further studies are therefore urgently required to examine whether the blood from khat chewers shows greater thrombogenecity and the likely mechanisms involved.

\section{Khat chewing, diabetes mellitus type II and appetite}

The general concept among Yemeni people, in particular diabetics, is that khat chewing controls the level of glucose in the blood and khat has a therapeutic role in the management of high blood glucose. The sympathomimetic actions of cathinone would be expected to raise plasma catecholamine levels. These catecholamines would increase blood glucose levels by activation of glycogenolysis in skeletal muscles and the liver; a $\beta_{2}$ adrenoceptor-mediated response. There is also inhibition of insulin release from the pancreatic $\beta$-cells via $\alpha_{2}$-adrenoceptor stimulation which would also elevate blood glucose levels (Broadley, 1996) (Fig. 5). While some studies show that in healthy non-diabetics, khat does not affect fasting or post-prandial serum glucose levels (Saif-Ali et al., 2003), others have suggested a decrease in serum glucose (Ramadan et al., 1979). In diabetic subjects, however, serum glucose was significantly higher after 1 and $2 \mathrm{~h}$ of khat chewing (Saif-Ali et al., 2003). Rabbits fed a diet containing different levels of khat leaves showed an increase in plasma glucose levels after 4 months but a significant reduction after 6 months (Al-Habori and Al-Mamary, 2004). These results are difficult to interpret but indicate the complex relationships between the stimulation of gly- 
gogenolysis by raised catecholamine levels and the effects of raising glucose on insulin release. Raised glucose levels will result in compensatory increases in insulin release. This study also showed that feeding rabbits with khat caused a significant reduction in plasma cholesterol throughout the 6-month period (Al-Habori and $\mathrm{Al}$ Mamary, 2004). This of course would be a favourable consequence of khat chewing in the context of cardiovascular risk. Clearly, our knowledge about the effects of cathinone and khat chewing on plasma glucose and insulin levels is very sparse and controlled studies need to be undertaken. These should examine the effects of acute cathinone administration and khat chewing on fasting levels of glucose, insulin and adrenaline in the serum. The effects of $\alpha_{2}$ and $\beta$-adrenoceptor antagonists on these changes could then be examined to dissect out the possible mechanisms and interactions between these factors.

Effects of khat chewing on appetite may also indirectly influence blood glucose levels and body weight. Recently, Murray et al. (2008) showed chewing khat to significantly decrease subjective feelings of hunger and increase the sensation of fullness but had no effect on ghrelin and peptide YY levels. They concluded that the anorexigenic effect of khat may be secondary to central mechanisms mediated via cathinone. Indeed, one of its uses is in the control of obesity, which indirectly would reduce the risk of diabetes. High plasma levels of the anorectic hormone, leptin, have been found $4 \mathrm{~h}$ after a heavy khat chewing session $(400 \mathrm{~g})$. This hormone may then contribute to the decreased appetite and body weight observed in khat chewers (Al-Dubai et al., 2006).

\section{Effects of khat chewing on the gastrointestinal tract and liver}

In the gastrointestinal tract, the astringent characteristics of the tannins in khat accounts for periodontal disease, stomatitis, oesophagitis and gastritis (WHO, 1980). Delay to intestinal absorption contributes to some degree to malnutrition. Tannins and norpseudoephdrine contribute to constipation, the most common medical complaint of the khat user. In a randomisedcontrolled trial, Heymann et al. (1995) reported a delay in gastric emptying after chewing khat, which was attributed to the sympathomimetic action of the cathinone. Moreover, Gunaid et al. (1999) showed khat to prolong whole gut transit and Makonnen (2000) reported that khat produced constipation in mice and an antispasmodic action on guinea-pig isolated ileum. The antispasmodic effect of khat extract was observed to be similar to that of D-amphetamine. Khat chewing has also been shown to be a risk factor for duodenal ulcers (Raja'a et al., 2000). The casecontrol study compared 175 Yemeni subjects with duodenal ulcers with 150 controls with no evidence of duodenal ulcers from gastroduodenoscopy. 133 (76\%) of the cases were khat chewers whereas only 52 (35\%) of controls were chewers. Other confounding variables, such as smoking, non-steroidal anti-inflammatory drug (NSAID) and alcohol consumption, however, were equally distributed between cases and controls and could be eliminated as causative factors. The authors concluded that khat chewing was significantly associated with duodenal ulcer. They could not identify the causative factor, suggesting one or more from; Helicobacter pylori associated with khat chewing, beverages consumed during khat chewing sessions, pesticides and other chemicals on the leaves, or the chemical constituents of khat such as cathinone or cathine. Further studies are required to eliminate each of these factors.

Short- and long-term toxicological effects of khat leaves have been tested in laboratory animals for a period of 6 months (AlHabori et al., 2002; Al-Mamary et al., 2002). The liver biochemical and histological parameters were found to be significantly altered

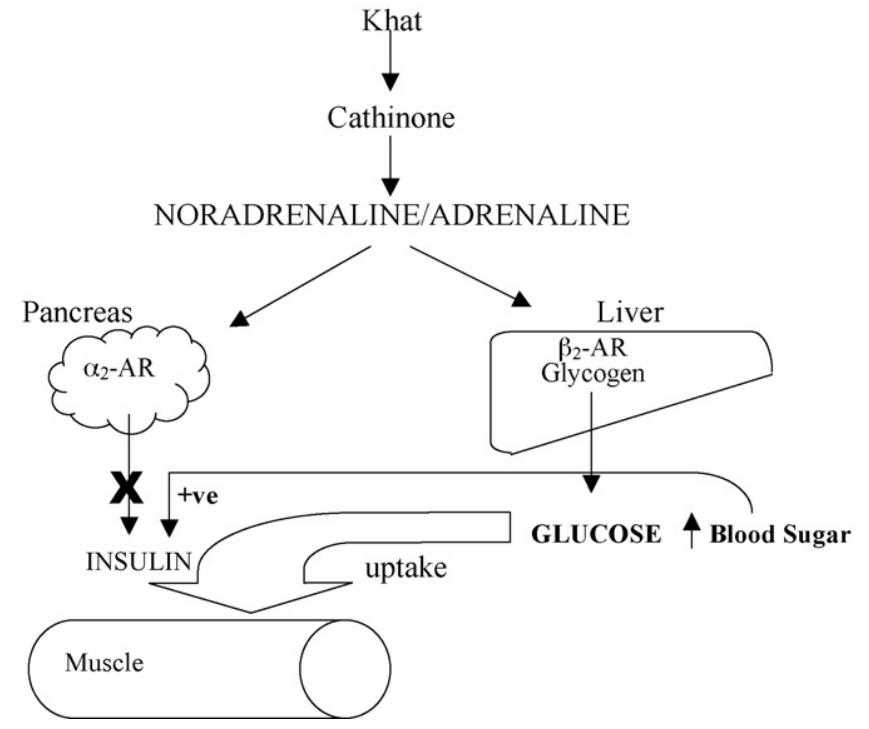

Fig. 5. Diagram of the hypothetical effects of khat and cathinone on blood sugar levels. Cathinone releases catecholamines (noradrenaline/adrenaline) which activate $\beta_{2}$-adrenoceptors ( $\beta_{2}$-AR) in the liver to induce glycogenolysis of glycogen to glucose. They also activate pancreatic $\alpha_{2}$-adrenoceptors $\left(\alpha_{2}\right.$-AR) to inhibit insulin release, which normally increases glucose uptake by skeletal muscle; the inhibition of insulin therefore results in increased blood sugar. High blood sugar induces insulin release to enhance uptake of the elevated glucose levels.

with a profound impact on the alkaline phosphatase and alanine aminotransferease plasma levels throughout the treatment period. Histopathological analysis showed evidence of congestion of the central liver veins as well as acute hepatocellular degeneration and regenerative activities, with porto-portal fibrosis. The consequence of this would be spreading fibrosis leading to nodularity of the liver and eventually cirrhosis. A vasoconstrictor action of cathinone would also contribute to this liver pathology. In confirmation of the hepatotoxicity of khat ingestion, a case report described an East African man with a regular khat chewing habit who developed jaundice as a result of acute hepatitis (Brostoff et al., 2006). Another report also described a patient with impaired liver function attributed to khat chewing (Saha and Dollery, 2006). More recently, severe acute liver injury has been attributed to khat chewing in the USA (Chapman et al., 2010). A case series described jaundice and deranged liver function based on biopsy histology and serum biochemistry in 7 UK men of Somali origin who were regular khat chewers. All denied any alcohol consumption and no other aetiological factors could be identified (Peevers et al., 2010). A rather unusual adverse effect on the liver of chewing khat was a parasitic infection of the liver by Fasciola hepatica as a contaminant of the khat leaves (Cats et al., 2000). Kidney lesions have also been described with fat droplets in the upper cortical tubules, acute cellular swelling and acute tubular nephrosis (AlMamary et al., 2002; Al-Habori et al., 2002). Administration of khat extracts showed a deranged systemic capacity to handle oxidative radicals and induces cytotoxic effects in cells of liver and kidney (Al-Habori, 2005). The khat dose levels used in these studies were high and equivalent to chewing 750-2000 g. Further histopathological analysis on the gastrointestinal tract showed no effect of khat on the oesophagus as evident by the regular thickness of the squamous epithelial mucosa, on the stomach as evident by the regular architecture of the glands of the gastric mucosa as well as normal submucosa and muscularis, and the intestinal tract as evident by the appearance of normal regular size and shape of villi (Al-Aghbari et al., 2004). 


\section{Khat chewing and other peripheral systems}

On the bladder, khat chewing produced a fall in urinary flow rate, an effect that has been shown to be inhibited by the selective $\alpha_{1-}$ adrenoceptor antagonist, indoramine, and therefore attributed to activation of this receptor subtype (Nasher et al., 1995). An increase in the prevalence of gallstones has been reported in the Middle East and Yemen but whether this is due to khat consumption is not known. However, gallbladder motility was found to be unaffected by acute khat chewing in healthy volunteers (Murugan et al., 2003). Khat leaves are traditionally considered to be a herbal remedy to alleviate respiratory disease symptoms and therefore may have effects on the airways (Al-Meshal et al., 1985). Little work has been undertaken on the airways effects of khat or cathinone. Cathinone did not cause direct contraction or relaxation of guinea-pig isolated trachea. However, in human and guinea-pig trachea, cathinone inhibited contractions induced via parasympathetic nerve electrical stimulation. This was attributed to inhibition of transmitter (acetylcholine) release from parasympathetic nerves innervating the airway at presynaptic $\alpha_{2}$-adrenoceptors and 5-HT receptors (Freund-Michel et al., 2008). Thus, an inhibitory effect on bronchospasm due to parasympathetic nerve activity in the airways may explain the historical benefits of khat in respiratory diseases.

Khat chewing has an adverse effect on reproductive functions (Mwenda et al., 2003). Khat chewing during pregnancy has a detrimental effect on the foetus, leading to low birth weight, teratogenic effects and infant mortality (Mwenda et al., 2003). Malformations of the visceral and skeletal structures together with growth retardation of the offspring were observed after administration of khat and khat extracts to pregnant rats from 5 to 15 days of gestation (Islam et al., 1994). Khat chewing affects male sexual potency by inhibiting spermatogenesis and affecting testosterone levels. Male rabbits fed khat extract for 5 weeks showed significantly reduced plasma testosterone levels and raised cortisol, to explain impaired reproductive function (Nyongesa et al., 2008). In a contrasting study, crude khat extract fed to olive baboons weekly for 2 months caused increased serum levels of testosterone but falls in prolactin and cortisol (Mwenda et al., 2006). However, these studies examined extracts of khat, the constituents of which were unidentified. An evaluation of cathinone in rats showed a decrease in sperm count, an increase in number of abnormal sperms and a decrease in plasma testosterone (Islam et al., 1990). Thus, there are conflicting results on the effects on male sexual function of khat and its main constituent, cathinone. Further studies are warranted to clarify this ambiguity using both cathinone and khat, since they may have opposing actions.

\section{Conclusion}

Khat is now widely chewed as a recreational drug in the Horn of Africa and the Arabian Peninsula and nowadays by expatriate communities living in Europe and North America. Traditionally khat chewing has been viewed as an aid to relieving fatigue and has some place in self-medication of depression (Deyessa et al., 2008). However, the WHO concludes that it has no therapeutic potential (WHO, 2006). While the psychological effects of chronic khat use have been the subject of much debate on its influence of social structure, there is now mounting cause for concern over the health effects on a wide range of peripheral organs. In Yemen, but not Djibouti, expenditure on khat is often at the expense of food (Milanovik, 2008). This review has identified a wide range of adverse effects on the cardiovascular, gastrointestinal and other peripheral systems. The evidence, however, is often based on limited numbers of case reports and only few prospective controlled studies have been undertaken. There is an urgent need for more thorough case-control studies to be performed to examine the role of khat in the aetiology of a number of diseases of peripheral organs, including cardiomyopathy, vascular disease such as cerebrovascular ischaemia and thromboembolism, diabetes, sexual function, duodenal ulcer and hepatitis. There are several issues that need to be addressed in future studies. Confounding issues, other than khat chewing, need to be eliminated as causative factors such as concomitant tobacco smoking, alcohol consumption, coexisting disease states, diet and obesity. Some of these have been mentioned in the discussions above. There is also a need to identify the causative factor(s) arising from the khat. For example, are the adverse health effects due to the cathinone content of the khat leaves? This could prove difficult to evaluate in human studies since it is unethical and illegal to administer cathinone to human subjects and would therefore be more appropriate to examine in animal studies. As pointed out on several occasions above, contaminants of the khat leaves such as pesticides may be responsible for some of the changes and these need to be eliminated in future studies by using chemical-free khat only in any prospective trials. While validity of much of our current knowledge on the health effects of khat chewing can be questioned, there are clear trends of adverse effects in a number of peripheral organs and these provide a warning to those in authority that efforts should be made to restrict the use of khat and to support more comprehensive evaluation of its health effects.

\section{References}

Ageely, H.M., 2009. Prevalence of khat chewing in college and secondary (high) school students of Jazan region, Saudi Arabia. Harm Reduction Journal 6, 11.

Al-Aghbari, A., Al-Thobhani, A., Al-Mamary, M., Al-Habori, M., Baker, M., 2004. A histopathological investigation of Catha edulis leaves: a long term feeding experiment in animals. Sana'a University Journal of Medical Science 1, 8-15.

Al-Attas, O., 1981. Khat Constituents, Neurological and Medical Effect. Khat in Life of Yemen and Yemenis. The Yemeni Research and Study Centre, Sanaa, Yemen, pp. 99-110.

Al-Dubai, W., Al-Habori, M., Al-Geiry, A., 2006. Human khat (Catha edulis) chewers have elevated plasma leptin and nonesterified fatty acids. Nutritional Research $26,632-636$.

Alem, A., Shibre, T., 1997. Khat induced psychosis and its medico-legal implication: a case report. Ethiopian Medical Journal 35, 137-139.

Alem, A., Kebede, D., Kullgren, G., 1999. The prevalence and socio-demographic correlates of khat chewing in Butajira, Ethiopia. Acta Psychiatrica Scandinavica 397 (Suppl.), 84-91.

Al-Habori, M., 2005. The potential adverse effects of habitual use of Catha edulis (khat). Expert Opinion on Drug Safety 4, 1145-1154.

Al-Habori, M., Al-Mamary, M., 2004. Long term feeding effects of Catha edulis leaves on blood constituents in animals. Phytomedicine 11, 639-644.

Al-Habori, M., Al-Aghbari, A., Al-Mamary, M., Baker, M., 2002. Toxicological evaluation of Catha edulis leaves: a long term feeding experiment in animals. Journal of Ethnopharmacology 83, 209-217.

Al-Hadrani, A.M., 2000. Khat-induced hemorrhoidal disease in Yemen. Saudi Medical Journal 21, 474-477.

Alkadi, H.O., Noman, M.A., Al-Thobhani, A.K., Al-Mekhlafi, F.S., Raja'a, Y.A., 2002 Clinical and experimental evaluation of the effect of khat-induced myocardial infarction. Saudi Medical Journal 23, 1195-1198.

Alkadi, H.O., Al-Kamarany, M., Al-Kadi, H., Lyoussi, B., Khalil, K.A., 2008. Khat-aspirin interaction. Yemen Journal of Pharmaceutical and Biological Science 2, 32-39.

Al-Mamary, M., Al-Habori, M., Al-Aghbari, A., Baker, M., 2002. Investigation into the toxicological effects of Catha edulis leaves: a short term study in animals. Phytotherapy Research 16, 127-132.

Al-Meshal, I.A., Ageel, A.M., Parmar, N.S., Tariq, M., 1985. Catha edulis (khat): use, abuse and current status of scientific knowledge. Filoterapia 56, 131-152.

Al-Motarreb, A., Broadley, K.J., 2003. Coronary and aortic vasoconstriction by cathinone, the active constituent of khat. Autonomic and Autacoid Pharmacology 23 319-326.

Al-Motarreb, A., Baker, K., Broadley, K.J., 2002a. Khat: pharmacological and medical aspects and its social use in Yemen. Phytotherapy Research 16, 403-413.

Al-Motarreb, A., Al-Kibsi, M., Al-Adhi, B., Broadley, K.J., 2002b. Khat chewing and acute myocardial infarction. Heart 87, 279-280.

Al-Motarreb, A., Briancon, S., Al-Jaber, N., Al-Adhi, B., Al-Jailani, F., Salek, M.S. Broadley, K.J., 2005. Khat chewing is a risk factor for acute myocardial infarction: a case-control study. British Journal of Clinical Pharmacology 59, 574-581.

Al-Saadi, M.M., Grigorov, M., 2004. The role of the plant Catha edulis in the occurance of dilated cardiomyopathy-cases in Yemen. Medical Review 40,61-64. 
Al-Samarraie, M., Khiabani, H.Z., Opdal, M.S., 2007. Khat-a new drug of abuse in Norway. Tidsskr Nor Laegeforen 127, 574-576.

Baker, K.E., Herbert, A.A., Broadley, K.J., 2007. Vasoconstriction of porcine left anterior descending coronary artery by ecstasy and cathinone is not an indirect sympathomimetic effect. Vascular Pharmacology 47, 10-17.

$\mathrm{BBC}, 2006$. Heart warning on African herb use. http://news.bbc.co.uk/1/hi/ health/5021210.stm.

Belew, M., Kebede, D., Kassaye, M., Enquoselassie, F., 2000. The magnitude of khat use and its association with health, nutrition and socio-economic status. Ethiopian Medical Journal 38, 11-26.

Bentur, Y., Bloom-Krasik, A., Raikhlin-Eisenkraft, B., 2008. Illicit cathinone ("Hagigat") poisoning. Clinical Toxicology (phila) 46, 206-210.

Brenneisen, R., Geisshusler, S., Schorno, X., 1986. Metabolism of cathinone to (-)-norephedrine and (-)-norpseudoephedrine. Journal of Pharmacy and Pharmacology 38, 298-300.

Brenneisen, R., Fisch, H.U., Koelbing, U., Geisshusler, S., Kalix, P., 1990. Ampetaminelike effects in humans of the khat alkaloid cathinone. British Journal of Clinical Pharmacology 30, 825-828.

Broadley, K.J., 1996. Autonomic Pharmacology. Taylor \& Francis, London.

Brostoff, J.M., Plymen, C., Birns, J., 2006. Khat-a novel cuse of drug-induiced hepatitis. European Journal of Internal Medicine 17, 383

Bruno, A., 2003. Cerebrovascular complications of alcohol and sympathomimetic drug abuse. Current Neurology and Neuroscience Reports 3, 40-45.

Bunzow, J.R., Sonders, M.S., Arttamangkul, S., Harrison, L.M., Zhang, G., Quigley, D.I., Darland, T., Suchland, K.L., Pasumamula, S., Kennedy, J.L., Olson, S.B., Magenis, E., Amara, S.G., Grandy, D.K., 2001. Amphetamine, 3,4 methylenedioxymethamphetamine, lysergic acid diethylamide, and metabolites of the catecholamine neurotransmitters are agonists of a rat trace amine receptor. Molecular Pharmacology 60, 1181-1188.

Call, T.D., Hartneck, J., Dickinson, W.A., Hartman, C.W., Bartel, A.G., 1982. Acute cardiomyopathy secondary to intravenous amphetamine abuse. Annals of Internal Medicine 97, 559-560.

Cats, A., Scholten, P., Meuwissen, S.G.M., Kuipers, E.J., 2000. Acute Fasciola hepatica infection attributed to khat chewing. Gut 47, 584-585

Chapman, M.H., Kajihara, M., Borges, G., O’Beirne, J., Patch, D., Dhillon, A.P., Crozier, A., Morgan, M.Y., 2010. Severe, acute liver injury and khat leaves. New England Journal of Medicine 362, 1642-1644.

Cox, G., Rampes, H., 2003. Adverse effects of khat: a review. Advances in Psychiatric Treatment 9, 456-463.

Crean, A.M., Pohl, J.E.F., 2004. Ally McBeal heart? Drug induced cardiomyopathy in a young woman. British Journal of Clinical Pharmacology 58, 558-559.

de Ridder, S., Eerens, F., Hofstra, L., 2007a. Khat rings twice: khat-induced thrombosis in two vascular territories. Netherland Heart Journal 15, 269-270.

de Ridder, S., Eerens, F., Hofstra, L., 2007b. Khat rings twice: khat-induced thrombosis in two vascular territories. Netherlands Heart Journal 15, 269-270.

Degraeve, G., 2007. Khat-induced psychosis? Tijdschrift voor Psychiatrie 49, $763-767$.

Detry, J.M., Vincent, M., 1992. Circadian rhythms in cardiovascular disease: the crucial hours. Journal of Human Hypertension 6, S3-S8.

Deyessa, N., Berhane, Y., Alem, A., Hogberg, U., Kullgren, G., 2008. Depression among women in rural Ethiopia as related to socioeconomic factors: a communitybased study on women in reproductive age groups. Scandinavian Journal of Public Health 36, 589-597.

El-Tahir, K.E.H., 1990. Narcotic and Mind-manifesting Drugs. College of Pharmacy, King Saud University, Riyadh, Kingdom of Saudi Arabia.

El-Wajeh, Y.A., Thornhill, M.H., 2009. Qat and its health effects. British Dental Journal 206, 17-21.

Feyissa, A.M., Kelly, J.P., 2008. A review of the neuropharmacological properties of khat. Progress in Neuropsychopharmacology. Biology Psychiatry 32,1147-1166.

Freund-Michel, V.C., Birrell, M.A., Patel, H.J., Murray-Lyon, I.M., Belvisi, M.G., 2008. Modulation of cholinergic contractions of airway smooth muscle by cathinone: potential beneficial effects in airway diseases. European Respiratory Journal 32 579-584.

Griffiths, P., 1998. Qat use in London: A Study of qat use Among a Sample of Somalis living in London. Home Office Drugs Prevention Initiative, Home Office, London.

Gugelmann, R., von Allmen, M., Brenneisen, R., Porzig, H., 1985. Quantitative differences in the pharmacological effects of $(+)$ - and (-)-cathinone. Experientia 41, $1568-1571$.

Gunaid, A.A., El-Khally, F.M., Hassan, N.A., Murray-Lyon, I.M., 1999. Chewing qat leaves slows the whole gut transit time. Saudi Medical Journal 20, 444-447.

Halbach, H., 1972. Medical aspects of the chewing of khat leaves. Bulletin WHO 47 21-29.

Halket, J.M., Karasu, Z., Murray-Lyon, I.M., 1995. Plasma cathinone levels following chewing khat leaves (Catha edulis Forsk.). Journal of Ethnopharmacology 49, 111-113.

Hassan, N.A., Gunaid, A.A., Abdo Rabbo, A.A., Abdel-Kader, Z.Y., Al-Awad, A.Y. Murray-Lyon, I.M., 2000. The effect of khat chewing on blood pressure and heart rate in healthy volunteers. Tropical Doctor 30, 107-108.

Hassan, N.A., Gunaid, A.A., El-Khally, F.M., Murray-Lyon, I.M., 2002. The effect of chewing Khat leaves on human mood. Saudi Medical Journal 23, 850-883.

Hassan, N.A., Gunaid, A.A., El-Khally, F.M., Al-Noami, M.Y., Murray-Lyon, I.M., 2005 Khat chewing and arterial blood pressure. A randomized controlled clinical trial of alpha-1 and beta-1 adrenoceptor blockade. Saudi Medical Journal 26, 537-541.

Hassan, N.A., Gunaid, A.A., Murray-Lyon, I.M., 2007. Khat (Catha edulis): health aspects of khat chewing. East Mediterranean Health Journal 13, 706-718.
Heymann, T.D., Bhupulan, A., Zureikat, N.E., Drinkwater, C., Giles, P., Murray-Lyon, I.M., 1995. Khat chewing delays gastric emptying of a semi-solid meal. Alimentary Pharmacology and Therapeutics 9, 81-83.

Holligan, A., 2009. Khat use spreads to British youth. BBC World Service, online news March 16 (http://news.bbc.co.uk/1/hi/uk/7942432.stm).

Houghton, P., 2004. Khat-a growing concern in the UK. Pharmaceutical Journal 272, 163-165.

Islam, M.W., Tariq, M., Ageel, A.M., El-Feraly, F.S., Al-Meshal, I.A., Ashraf, I., 1990. An evaluation of the male reproductive toxicity of cathinone. Toxicology 60, 223-234.

Islam, M.W., Al-Shabanah, O.A., Al-Harbi, M.M., Al-Gharably, N.M., 1994. Evaluation of teratogenic potential of khat (Catha edulis Forsk.) in rats. Drug and Chemical Toxicology 17, 51-68.

Jager, A.D., Sireling, L., 1994. Natural history of khat psychosis. Australian and New Zealand Journal of Psychiatry 28, 331-332.

Kalix, P., 1983. Effect of the alkaloid cathinone on the release of radioactivity from rabbit atria prelabelled with ${ }^{3} \mathrm{H}$-norepinephrine. Life Sciences 32, 801-807.

Kalix, P., 1984. The pharmacology of khat. General Pharmacology 15, 179-187.

Kalix, P., 1988. Khat: a plant with amphetamine effect. Journal of Substance Abuse Treatment 5, 163-169.

Kalix, P., 1992. Cathinone, a natural amphetamine. Pharmacology and Toxicology 70, 77-86.

Kalix, P., 1996. Catha edulis, a plant that has amphetamine effects. Pharmacy World \& Science 18, 69-73

Kalix, P., Braenden, O., 1985. Pharmacological aspects of the chewing of khat leaves. Pharmacological Reviews 37, 149-164.

Kassim, S., Croucher, R., 2006. Khat chewing amongst UK resident male Yemeni adults: an exploratory study. International Dental Journal 56, 97-101.

Khalil, N., 1997. Yemeni women and qat. Al-Thawabit (Qat and Yemeni Society) 8 157-167.

Kohli, J., Goldberg, L., 1982. Cardiovascular effects of $(-)$ cathinone in the anaesthetized dog: comparison with (+) amphetamine. Journal of Pharmacy and Pharmacology 34, 338-340.

Laswar, A.K., Darwish, A.K., 2009. Prevalence of cigarette smoking and khat chewing among Aden University medical students and their relationship to BP and body mass index. Saudi Journal of Kidney Disease and Transplantation 20, 862866.

Lugman, W., Danowski, T., 1976. The use of khat in Yemen: social and medical observations. Annals of Internal Medicine 85, 245-249.

Makonnen, E., 2000. Constipating and spasmolytic effects of khat (Catha edulis Forsk) in experimental animals. Phytomedicine 74, 309-312.

Manghi, R.A., Broers, B., Khan, R., Benguettat, D., Khazaal, Y., Zullino, D.F., 2009. Khat use: lifestyle or addiction? Journal of Psychoactive Drugs 41, 1-10.

Milanovik, B., 2008. Qat expenditure in Yemen and Djibouti: an empirical analysis. Journal of African Economics 17, 661-687.

Mujalli, H.M., Bo, X., Zhang, L., 2005. The effect of khat (Catha edulis) on acute cerebral infarction. Neurosciences 10, 219-222.

Murray, C.D., Le Roux, C.W., Emmanuel, A.V., Halket, J.M., Przyborowska, A.M., Kamm, M.A., Murray-Lyon, I.M., 2008. The effect of khat (Catha edulis) as an appetite suppressant is independent of ghrelin and PYY secretion. Appetite 51, 747-750.

Murugan, N., Burkhill, G., Williams, S.G., Padley, S.P., Murray-Lyon, I.M., 2003. The effect of khat chewing on gallbladder motility in a group of volunteers. Journal of Ethnopharmacology 86, 225-227.

Mwenda, J.M., Arimi, M.M., Kyama, M.C., Langat, D.K., 2003. Effects of khat (Catha edulis) consumption on reproductive functions: a review. East African Medical Journal 81, 318-323.

Mwenda, J.M., Owuor, R.A., Kyama, C.M., Wango, E.O., M’Arimi, M., Langat, D.K., 2006. Khat (Catha edulis) up-regulates testosterone and decreases prolactin and cortisol levels in baboon. Journal of Ethnopharmacology 103, 379-384.

Nasher, A.A., Qirbi, A.A., Ghafoor, M.A., Catterall, A., Thompson, A., Ramsay, J.W., Murray-Lyon, I.M., 1995. Khat chewing and bladder neck dysfunction. A randomized control trial of $\alpha$-adrenergic blockade. British Journal of Urology 75 , 597-598.

Nyongesa, A.W., Patel, N.B., Onyango, D.W., Odongo, D.W., Wango, E.O., 2008. Khat (Catha edulis) lowers plasma luteinizing hormone (LH) and testosterone secretion, but increases cortisol levels in male rabbits. Journal of Ethnopharmacology $116,245-250$

Odenwald, M., Neuner, F., Schauer, M., Elbert, T., Catani, C., Lingenfelder, B., Hinkel, H., Hafner, H., Rockstroh, B., 2005. Khat use as risk factor for psychotic disorders: a cross-sectional and case-control study in Somalia. BMC Medicine 12, 3-5.

Pantelis, C., Hindler, C.G., Taylor, J.C., 1989. Use and abuse of khat (Catha edulis): a review of the distribution, pharmacology, side effects and a description of psychosis attributed to khat chewing. Psychological Medicine 19,657-668.

Patel, S.L., Wright, S., Gammampila, A., 2005. Khat use among Somalis in four English cities. Home Office Report 47/05

Peevers, C.G., Moorghen, M., Collins, P.L., Gordon, F.H., McCune, C.A., 2010. Liver disease and cirrhosis because of khat chewing in UK Somali men: a case series. Liver International doi:10.1111/j.1478-3231.2010.02228.x.

Pennings, E.J., Opperhuizen, A., van Amsterdam, J.G., 2008. Risk assessment of khat use in the Netherlands: a review based on adverse health effects, prevalence, criminal involvement and public order. Regulatory Toxicology and Pharmacology 52, 199-207.

Raja'a, Y.A., Noman, T.A., Al-Warafi, A.K., Al-Mashraki, N.A., Al-Yosofi, A.M., 2000 Khat chewing is a risk factor of duodenal ulcer. Saudi Medical Journal 21, 887-888. 
Ramadan, M.A., Tash, F.M., Fahmi, M., Abul-kheir, F.A., 1979. Metabolism changes caused by khat consumption in Yemen. Journal of Yemen Centre for Studies and Research 3, 35-44.

Raman, R., 1983. Catha edulis Forsk., Geographical dispersal, Botanical, Ecological and Agronomical Aspects with Special References to Yemen Arab Republic. PhD Thesis, University of Gottingen, Germany.

Saha, S., Dollery, C., 2006. Severe ischaemic cardiomyopathy associated with khat chewing. Journal of the Royal Society of Medicine 99, 316-318.

Saif-Ali, R., Al-Qiribi, A., Al-Geiry, A., Al-Habori, M., 2003. Effect of Catha edulis on plasma glucose and C-peptide in both type 2 diabetics and non-diabetics. Journal of Ethnopharmacology 86, 45-49.

Selwyn, A.P., Raby, K., Vita, J.A., Ganz, P., Yeung, A., 1991. Diurnal rhythms and clinical events in coronary artery disease. Postgraduate Medical Journal 67, S44S47.

Smith, H.J., Roche, A.H.G., Jagusch, M.F., Herdson, P.B., 1976. Cardiomyopathy associated with amphetamine administration. American Heart Journal 91 792-797.
Stefan, J., Mathew, B., 2005. Khat chewing: an emerging drug concern in Australia? Australian and New Zealand Journal of Psychiatry 39, 842-843.

Tesfaye, F., Byass, P., Wall, S., Berhane, Y., Bonita, R., 2008. Association of smoking and khat (Catha edulis Forsk) use with high blood pressure among adults in Addis Ababa, Ethiopia, 2006. Preventing Chronic Disease 5, A89.

Vanwalleghem, I.E., Vanwalleghem, P.W., De Bleecker, J.L., 2006. Khat chewing can cause stroke. Cerebrovascular Disease 22, 198-200.

Westover, A.N., Nakonezny, P.A., Haaaaley, R.W., 2008. Acute myocardial infarction in young adults who abuse amphetamines. Drug and Alcohol Dependence 96, 49-56.

WHO Advisory Group, 1980. Review of the pharmacology of khat. Bulletin on Narcotics 32, 83-93.

WHO Expert Committee on Drug Dependence, 2006. Thirty Fourth Report. WHO Technical Report Series, Report 942, Geneva.

Widler, P., Mathys, K., Brenneisen, R., Kalix, P., Fisch, H.-U., 1994. Pharmacodynamics and pharmacokinetics of khat: a controlled study. Clinical Pharmacology and Therapeutics 55, 556-562. 